\section{Buddhism is no bar to an open mind. Is science?}

SIR - I was appalled to learn, through your News story "Neuroscientists see red over Dalai Lama” (Nature 436, 453; 2005), of a petition by a group of neuroscientists to cancel a lecture by the Dalai Lama scheduled for the November meeting of the Society for Neuroscience.

What are the motives behind this petition? If the research itself is controversial, then the controversies should be aired at this meeting. The Dalai Lama is fully capable of scientific discussion, as reported in an earlier News Feature "Buddhism on the brain" (Nature 432, 670; 2005). Asked what would happen if neuroscience came up with information that directly contradicted Buddhist philosophy, the Dalai Lama is quoted as answering: "Then we would have to change the philosophy to match the science". What is the harm in listening to a man, religious figure or not, who is so open-minded?

Robert Desimone's statement that the Society for Neuroscience should "distance itself as much as it can from the Dalai Lama and his beliefs" is also unjustifiable. In the past year, the Dalai Lama has spoken in favour of scientific truth-seeking, human rights, species conservation and peace. If these are things that we, as scientists, need to distance ourselves from, then perhaps we deserve the damaging stereotypes we are given in the popular media.

\section{Janis L. Dickinson}

Hastings Natural History Reservation, Museum of Vertebrate Zoology, University of California, Berkeley, 38601 Carmel Valley Road, Carmel Valley, California 93924, USA

\section{Power-plant design should prepare for carbon capture}

SIR - Your News Feature "China's burning ambition” (Nature 435, 1152-1154; 2005) identifies gasification-based technologies as important for limiting future pollutant and $\mathrm{CO}_{2}$ emissions from China, but it fails to consider another major requirement for any future large-scale reduction strategy. There was no mention of $\mathrm{CO}_{2}$ capture and storage from the hundreds of new coal-combustion power plants that will inevitably be built in China during the coming decades. These modern power stations are likely to continue in use for about 50 years, and their combined emissions could exceed current UK emissions, for example, several times over.

As your News Feature notes, it would be very expensive to move immediately from combustion technologies to gasificationbased options for all new coal plants. Fortunately, this is not necessary to prepare for eventual $\mathrm{CO}_{2}$ capture and geological carbon sequestration from these actual plants. Modern combustion plants using supercritical steam conditions, like those now being built in China, have coal-to-electricity efficiencies that at least match those of integrated gasifier combined cycle plants. With the latest technologies, efficiency penalties for capture are now also comparable.

Building a new supercritical steam plant to be 'capture ready', so that $\mathrm{CO}_{2}$ capture can be added later with minimal cost and performance impacts, will add a negligible amount to the initial cost, but could reduce subsequent economic penalties for adding capture by perhaps a third.

With no market or regulatory drivers currently in China to make coal-combustion plants 'capture ready', the technology has received little or no attention there, although it is being actively considered by electricity utilities in Canada and the United Kingdom. Jon Gibbins

Energy Technology for Sustainable Development Group, Mechanical Engineering Department, Imperial College London, London SW7 2AZ, UK

\section{Answering the critics of Japanese whale research}

SIR - We wish to respond to a Commentary article by Nicholas J. Gales and colleagues, "Japan's whaling plan under scrutiny" (Nature 435, 883-884; 2005).

The title of the article inappropriately uses the term "whaling". Research on whales is conducted according to provisions of the International Convention for the Regulation of Whaling (ICRW) and is fundamentally different from commercial whaling.

It is true that the government issuing research permits may determine the sample size, and there is no requirement to change this on the advice of other governments. But Japan has submitted annual research plans to the Scientific Committee (SC) of the International Whaling Commission (IWC) for review and has incorporated amendments following any constructive suggestions from the SC. Gales and colleagues present their negative criticism of Japanese research as if this was the opinion of the SC. However, many positive comments have been made and reported by the SC over the years.

The authors condemn Japanese research on the basis of the number of whales captured since 1987. In planning our research, we must carefully determine the sample size that can achieve statistically valid results while also safeguarding population levels. Any criticism should address the rationale for calculating sample size, not merely highlight a number that seems large. Our research proposal describes this process clearly.

Criticism that science is being used as a cloak to hide the purpose of killing whales is inappropriate. The lethal method used for sampling is required to achieve our research objectives, including determination of age and detailed data on stomach contents. Also, parts of Japan's research programme use non-lethal techniques for sighting surveys and oceanographic studies, as well as biopsy sampling.

Contrary to the authors' comment that the publication record of our 18-year research programme is "very poor", we have made more than 150 scientific papers available to the SC and had a further 79 published in academic peer-reviewed journals. Unfortunately, many journals reject papers that report data from lethal whale sampling, even though they accept papers on other lethally sampled mammals.

In January 2005, the government of Japan held a meeting to review data and results from the previous 17 years of research (JARPA) in order to assist the planning of the new research programme (JARPA II). Many anti-whaling scientists, including the authors of the Commentary article, chose not to attend, although every member of the SC was invited. The Commentary claims that Japanese whale research is being conducted in an area designated as a sanctuary by the IWC. But the creation of this sanctuary was not recommended by the SC, and it was designed only to protect whales from commercial whaling.

Our new plan for Antarctic whale research (JARPA II) has been designed with farreaching objectives to ascertain the dynamics of the Antarctic ecosystem. The Commentary authors say this is a job for the Commission for the Conservation of Antarctic Marine Living Resources, but this organization does not conduct research on whales; Japan plans to collaborate with it to achieve JARPA II's research objectives. Japan has provided skilled labour, logistics and vessels to the IWC for large-scale Antarctic whale surveys conducted with multinational researchers.

Research of the magnitude of JARPA II is costly. Funds may be obtained by selling the by-products of whale research, according to Article 8 of the ICRW. Critics who say this makes the research a commercial enterprise are denying a provision of the ICRW.

Finally, the Commentary was written and published using information from the SC that, under IWC rules, should have remained confidential until the IWC's opening plenary session on 20 June.

Hiroshi Hatanaka

Institute of Cetacean Research, 4-5 Toyomi-Cho, Chuo-Ku, Tokyo, 104-0055, Japan

The Institute of Cetacean Research was offered an early opportunity to balance the Commentary published on 16 June with an accompanying article in the same issue, but declined Nature's offer - Editor, Nature. 